\title{
Dossier « Le réveil du dodo III » Biodiversity conservation: from research to action
}

\author{
Raphaël Arlettaz ${ }^{1}$, Raphaël Mathevet ${ }^{2}$
}

${ }^{1}$ Géographe et biologiste de la conservation, University of Bern, Institute of Ecology and Evolution, Division of Conservation Biology, CH-3012 Bern, Switzerland \& Swiss Ornithological Institute, Valais Field Station, Nature Centre, CH-3970 Salgesch, Switzerland

2 Écologue et géographe, CNRS, UMR5175 CEFE, Montpellier cedex 5, France

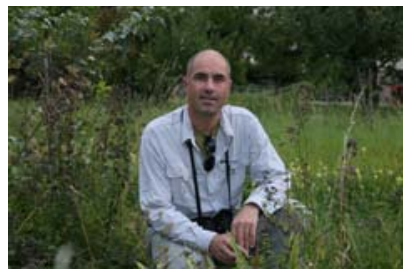

Raphaël Arlettaz est professeur et responsable de la division Biologie de la conservation de l'Institut d'écologie et d'évolution à l'Université de Berne. Ses centres d'intérêt sont divers et portent prioritairement sur la conservation et la restauration des écosystèmes agricoles et des écosystèmes alpins. Y sont étudiées les communautés végétales et animales, avec un accent particulier sur les espèces emblématiques de la faune vertébrée, notamment les oiseaux et les chauves-souris. Il est également directeur de l'antenne valaisanne de la station ornithologique suisse. Il est depuis toujours très engagé dans la mise en œuvre de mesures concrètes de sauvegarde de la biodiversité.

Raphaël Mathevet: Raphaël Arlettaz, you are professor of conservation biology at Bern University. Your main research interests are ecology and conservation biology, principally of birds and bats. You are also supervising the Valais field station of the famous Swiss Ornithological Institute in the Alps. For several years you have been fully engaged in biodiversity conservation in the field. Could you explain why you consider involvement in both biodiversity conservation research and action as a crucial issue?

Raphaël Arlettaz: The human enterprise is putting an immense, steadily increasing pressure on nature and biodiversity. This situation results both from the overexponential demographic expansion of Homo sapiens and from our extravagant pattern of consumption of natural resources. Actually it is the multiplication of these two mechanisms (unabated growth in population size and dramatic increase in per capita use of resources)

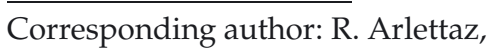

raphael.arlettaz@iee.unibe.ch

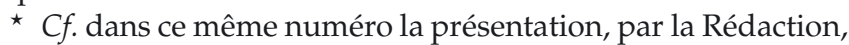
de ce dossier et de son contenu. that causes all our current environmental problems ${ }^{1}$. The over-exploitation of natural resources and the pollution that it generates start to exert massive impacts on the environment and on the biosphere. The fact that everybody contributes to this situation whilst nobody feels really responsible individually has been termed the tragedy of the commons ${ }^{2}$.

The efficiency of the human economy is due to an increasing share of the net primary productivity (NPP) appropriated by humans, mostly through agriculture. Currently, Homo sapiens monopolizes about $25 \%$ of the total biosphere NPP and $45-55 \%$ of the terrestrial $\mathrm{NPP}^{3}$.

\footnotetext{
${ }^{1}$ Cohen, J.E., 1995. Population growth and earth's human carrying capacity, Science, 269, 41-346.

2 Hardin, G., 1968. The tragedy of the commons, Science, 162, 1243-1248; Killingback, T., Bieri, J., Flatt, T., 2006. Evolution in group-structured populations can resolve the tragedy of the commons, Proceedings of the Royal Society, Series B, Biological sciences, 273, 1477-1481.

3 Vitousek, P.M., Mooney, H.A., Lubchenco, J., Melillo, J.M., 1997. Human domination of earth's ecosystems, Science, 277, 494-499; Haberl, H., Erb, K.H., Krausmann, F., Gaube, V., Bondeau, A., Plutzar, C., Gingrich, S., Lucht, W., FischerKowalski, M., 2007. Quantifying and mapping the human
} 


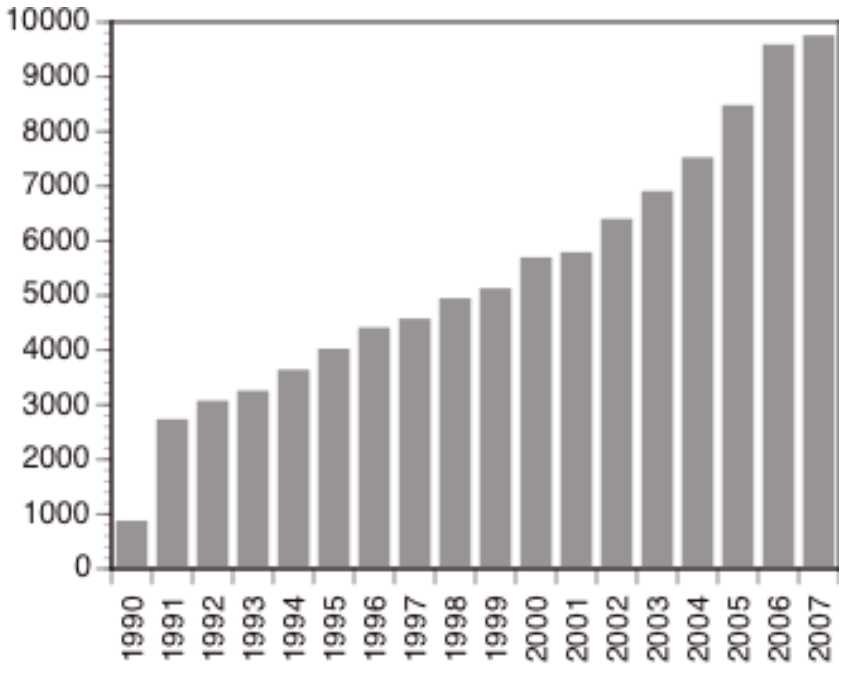

Fig. 1. Increase in the number of peer-reviewed articles published since 1990 in the areas of "conservation" and "ecological restoration" (keywords used in a search on Web of Science, Institute for Scientific Information; $n=96903$ records by the end of 2007).

A corresponding share of NPP is simply no longer available to other living organisms, i.e. biodiversity. Although most segments of human society are obsessed with economic growth, a few other segments want to preserve nature and biodiversity. The field for potential action remains narrow, however, given the extant constraints and drives in societies and economies. Yet, the sciences of biodiversity such as conservation biology and restoration ecology are here to provide some guidance. These new disciplines in the life sciences have undergone a frantic development, especially since the Earth Summit in 1992, which is reflected in the rapidly growing number of specialized journals and published articles in these fields (Fig. 1). These papers of course abound in recommendations and prescriptions for a better management of biodiversity. Yet, there is a positive correlation over time between the number of species of conservation concern on red lists and the number of peer-reviewed papers published, as well as a negative correlation between the Living Planet Index for vertebrate species and the number of those scientific articles (Fig. 2). In other words, it seems that the tons of conservation and restoration recommendations which are published do not increase implementation success. Are they even ever implemented in the real world? This discrepancy demonstrates the huge divide which exists between research and action in biodiversity conservation and restoration ${ }^{4}$, with most implemented conservation actions being based on intu-

appropriation of net primary production in earth's terrestrial ecosystems, Proceedings of the National Academy of Sciences of the United States of America, 104, 12942-12947.

4 Chapron, G., Arlettaz, R., 2008. Conservation: Academics should "conserve or perish", Nature, 451, 127-127.

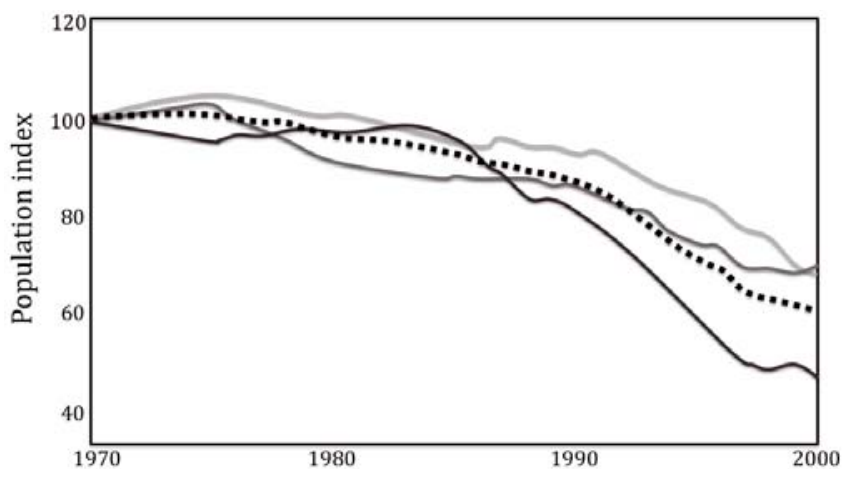

Fig. 2. Demographic trends between 1970 (index arbitrarily set at 100) and 2000 for reference terrestrial (solid light grey), marine (dark grey), freshwater (black) and all vertebrate species (dashed line) considered by the Living Planet Index monitoring scheme $(n=1313$ species in the most recent assessments). Redrawn from WWF website at http://www.panda.org/about_our_earth/all_ publications/living_planet_report/living_planet_index.

ition, subjective expert opinion if not trial and errors, rather than on scientific evidence ${ }^{5}$. As claimed in a recent editorial of Nature $e^{6}$ : "what is needed is a concerted effort by both academic scientists and practitioners to get out of their respective ruts".

R.M.: That was also the main objective of the "Retour du dodo" conference held in Montpellier in March 2009, to which you were invited for a keynote lecture. In two of your recent papers ${ }^{7}$ you called for paradigm shifts in the way conservation/restoration research performance is evaluated. According to you, in the future, new performance metrics must be developed which account for both the impact of publications and the impact of "public actions". During the last decade you developed several research and conservation activities in two institutions which work in tandem in an attempt to bridge this huge gap between research and action. What is this form of joint-venture and how do you deal with interdisciplinarity issues?

Raphaël Arlettaz: The joint-venture launched in 2002 involves an academic institution, the Division of Conservation Biology at Bern University, and a private foundation, the Swiss Ornithological Institute. The former runs mostly practice-oriented, applied research on the conservation and restoration of, among other organisms, endangered bird species, whilst the latter routinely

\footnotetext{
5 Sutherland, W.J., Pullin, A.S., Dolman, P.M., Knight, T.M., 2004. The need for evidence-based conservation, Trends in Ecology E Evolution, 19, 305-308.

6 Anonymous, 2007. The great divide, Nature, 450, 135-136.

7 Chapron, G., Arlettaz, R., op. cit.; Arlettaz, R., Schaub, M., Fournier, J., Reichlin, T.S., Sierro, A., Watson, J.E.M., Braunisch, V., 2010. From publications to public actions: When conservation biologists bridge the gap between research and implementation, BioScience, 60, 835-842.
} 
conducts population monitoring, carries out research which is mostly applied, and attempts to implement corrective conservation and restoration measures. The complementarity between these two instances, with myself being active on and even heading the two platforms, has led to some conservation successes already, and we can expect more successes in the near future with the results of applied, targeted research accumulating and progressively flowing into practice. Yet, not all our conservation projects launched so far have delivered positive outcomes in reality, although it is possibly a bit premature to make a definitive judgement. Yet, after seven years of activity, we can start questioning the validity of our approach, which is exclusively mono-disciplinary (all main actors involved have in common biology as educational background). Although our conservation and restoration recommendations are drawn from our peer-reviewed research, we sometimes failed to convince stakeholders, practitioners if not ecologist colleagues to implement the prescriptions we have formulated and in which we genuinely believe. The problem may to some extent be due to an absence of involvement of specialists from the social sciences in the process: from that viewpoint, I would say that our actions were often developed rather intuitively, with "common sense psychology" and personal basic social skills as main tools for approaching the various actors and stakeholders.

R.M.: Could you illustrate the kinds of socioeconomic problems you encountered in your integrated conservation and restoration projects? According to you what are the sociological limits and weaknesses of these projects?

Raphaël Arlettaz: I must say that I genuinely ignore whether contributions or even active involvement of specialists of the social sciences may have enhanced and may still enhance the chances of success of these projects. Again, our approach was exclusively mono-disciplinary and I have to confess that I even ignore the main modus operandi of social sciences. Thus, my main purpose here is to provoke some debate, some reaction from the specialists of the social sciences involved in environmental issues. Could they provide some pragmatic guidance for enhancing the chances of success of similar projects? If so, how would they operate in such endeavour? More specifically, I am curious to know whether we could have avoided some of the caveats we encountered if our projects had been framed differently from the outset. Can integration of sociological knowledge and commitment of specialists of that discipline improve the efficiency of conservation and restoration actions? Again, my interrogation is neither critical nor cynical: I am genuinely interested in knowing how we, as conservation biologists, could benefit from contributions from the social sciences.
R.M.: Hopefully, opening this debate could be a first attempt to bridge the divide that prevails between the biological and socio-economic aspects of conservation and restoration ecology of your case studies. Let us come to four of your research projects you find exemplary and would like to illustrate. You first worked on the Alpine timberline biodiversity. What are the main difficulties you encountered while trying to preserve Alpine timberline wildlife from the negative impacts of both the abandonment of traditional agricultural practices and the spreading of snow sport activities?

Raphaël Arlettaz: Alpine timberline ecosystems have been facing two main threats for decades: first, the detrimental effects associated with abandonment of traditional farming practices, which leads to progressive encroachment by the field-layer and finally by the forest, i.e. a loss of habitat heterogeneity which causes decline in biodiversity, including that of our study model, Black grouse; second, the spreading of recreation that impacts on habitats (e.g. ski resorts) and wildlife (e.g. disturbance by snow sports practitioners), including Black grouse, a species whose main habitat overlaps with traditional pastureland where most ski facilities are established in the Alps, and which therefore suffers from disturbance by humans in winter ${ }^{8}$. In order to mitigate these negative trends for Black grouse populations, we have developed evidence-based management concepts aiming both at revitalizing their breeding habitat through forestry measures ${ }^{9}$ to be applied in priority in areas with rapid shrub and forest encroachment and at creating winter refuges to reduce the impact of snow sports on these birds ${ }^{10}$. We thought our breeding habitat management programme would be difficult to implement because it requires managing the field layer, and would thus, we believed, not be well accepted by foresters who are very much focused on trees. This was without reckoning with the newly launched Swiss forest management policy that regulates the flux of subsidies from the federal state (Bern) to the cantons, which now stipulates forestry

\footnotetext{
8 Arlettaz, R., Patthey, P., Baltic, M., Leu, T., Schaub, M., Palme, R., Jenni-Eiermann, S., 2007. Spreading free-riding snow sports represent a novel serious threat for wildlife, Proceedings of the Royal Society, Series B, Biological sciences, 274, 1219-1224; Patthey, P., Wirthner, S., Signorell, N., Arlettaz, R., 2008. Impact of outdoor winter sports on the abundance of a key indicator species of alpine ecosystems, Journal of Applied Ecology, 45, 1704-1711.

9 Signorell, N., 2008. Habitat management guidelines for the conservation of an emblematic species of Alpine timberline ecosystems, the Black Grouse: from fine-grained habitat selection to large-scale habitat suitability modelling. PhD Thesis, University of Bern, Institute of Ecology and Evolution, Conservation Biology Division.

10 Braunisch, V., Patthey, P., Arlettaz, R., in press. Spatially explicit modelling of conflict zones between wildlife and outdoor snow-sports: Prioritizing areas for winter refuges, Ecological Applications.
} 
measures be targeted at biodiversity for obtaining federal subsidies. Although Black grouse is not a typical forest bird, but mostly a species occurring in semi-open, timberline ecosystems, we could convince the local authorities to put the species among the biodiversity targets for subalpine forests in the canton of Valais (SW Switzerland). The first action plans for mitigating shrub (Ericacea fieldlayer) and forest encroachment were implemented in autumn 2009, whilst we have just finished developing a spatially-explicit model (a mandate of the Valais forestry service to the University of Bern) which delineates areas with rapid encroachment where mitigation measures should be applied in priority ${ }^{11}$.

R.M.: This work demonstrates how changes in policies (more biodiversity-friendly management) and, especially, appropriate incentives may be decisive for boosting action. Without these changes, do you think you would have faced big problems in convincing the local authorities and foresters to adopt new management practices favourable to Black grouse?

Raphaël Arlettaz: Without mentioning the matter of financing the prescribed habitat interventions! It is not clear to me whether the participation of people from the social sciences would in this case have contributed to further improve our chances of success. This illustration exemplifies above all, in my opinion, the power of money for provoking rapid paradigm shifts in the conception of conservation and restoration programmes. An advantage of the Swiss Alpine forests is that they mostly belong to local public communities, which facilitates coordinated management and a direct implementation of appropriate management measures. The future will show whether the scale of the management interventions planned for Black grouse in Valais will suffice to restore its ideal breeding habitat matrix, i.e. if these measures can actually counteract the rapid shrinking of its preferred habitat configuration.

R.M.: I understood that on this specific topic you also worked on the creation of winter preserves. Did you have to face the same difficulties?

Raphaël Arlettaz: The situation seems to be more tricky regarding the creation of winter preserves although the Swiss federal state (Ministry for the Environment) is also involved, along with several stakeholders such as the Swiss Alpine Club, in the development of a new public campaign aimed at mitigating the negative effects of winter sports - especially rapidly

\footnotetext{
11 Patthey, P., Braunisch, V., Arlettaz, R., 2010. Localisation spatialement explicite des zones d'intervention prioritaires pour la gestion de la biodiversité à l'étage haut montagnard et subalpin supérieur : projet de gestion de l'habitat de reproduction du Tétras-lyre en Valais. Rapport pour le service des forêts et du paysage du canton du Valais, Sion, Suisse.
}

spreading off-piste activities such as back-country skiing, free-ride and snowshoeing - on wildlife ("RespekTiere deine Grenzen"; “Respecte tes limites!”; RespekTiere is a play on words: in German it means both "have respect and respect animals"). Winter preserves are about to be created throughout the Alps for a better preservation of sensitive wildlife. There is a risk, however, that these reserves will not be placed in the landscape where they would be really useful for endangered wildlife. This is largely due to the fact that most programmes being developed in different parts of the Swiss highlands are based on expert opinion rather than on scientific evidence. For Black grouse, which is certainly the species most affected by these snow sports activities in the Alps, we have developed, for the cantons of Valais and Vaud (SW Switzerland), a spatially-explicit model which shows where major conflicts between snow sports activities (both onpiste and off-piste traffic) and Black grouse currently occur, or are expected to take place in the future ${ }^{10}$. This model has enabled delineating 31 priority areas for creating optimally-placed winter refuges of some dozens of hectares each. This proposal to create 31 winter refuges has recently been addressed to the regional authorities in charge of wildlife management (cantonal game, fishery and wildlife service) with the hope that a top-down strategy will be developed to that purpose. The same document additionally suggests that winter refuges currently falling outside the perimeter of game reserves (about half of the 31 priority areas) should in the mid and long term benefit from a banning of any hunting activity. As a matter of fact, recent observations in the Bavarian Alps have shown that Black grouse become less elusive and may even increase in density within ski resorts where hunting is banned insofar as winter preserves are appropriately situated in the landscape. This is probably due to the fact that Black grouse may no longer associate humans with predators as soon as hunting is proscribed. In addition to the above top-down strategy that we are trying to stimulate, we are also going to directly (Swiss Ornithological Institute) approach ski resorts, skilift companies and Alpine clubs to convince them to adopt the same scheme for wildlife winter refuges. It is still uncertain, however, whether this complementary bottom-up strategy will incite the stakeholders to play the game. Particularly critical will in our opinion be the attitude of sportspeople, especially those practicing free-ride such as back-country skiing, ski mountaineering and snowboarding, when it comes to respect the perimeter of these future winter preserves. Actually, many free-riders do not hesitate to take considerable risks when crossing areas with avalanche hazards, this despite numerous warnings and a clear signalling of these dangers on the spot. Will free-riders, who seem to be so prone to risk their own life, give a damn about not trespassing the boundaries of wildlife winter refuges? 
R.M.: A thorough appraisal of the situation by sociologists would certainly be of great help to evaluate the chances of success of this programme. In the literature a lot of papers discussed the successes and failures of top-down and bottom-up approaches to biodiversity conservation. You also work on the mitigation of dangerous pylons which kill large birds in heavily anthropized landscapes. In this context you had to concretely deal with the issue of multiple decision-levels.

Raphaël Arlettaz: The modern landscape is characterized by widespread and dense infrastructure networks devoted to the transportation of humans, goods and energy. Infrastructure networks fragment habitats, isolating populations. They also represent pitfalls for some species, especially large flying animals such as raptors and storks which for instance collide with aerial cables or get electrocuted. We studied the effects of anthropogenic mortality due to modern infrastructure upon the demography of a small, but relatively stable population of Eagle owls in the Alps of Valais, Switzerland. We used for that several sources of information: 20 years of population censuses and assessments of reproductive success, data on mortality cause of birds found dead, fate of young radiotagged at the eyrie. The study shows that anthropogenic mortality is of serious conservation concern, especially electrocution on dangerous pylons ${ }^{12}$. This factor is the primary source of fatalities among Eagle owls, constituting about $50 \%$ of anthropogenic mortality. A demographic projection establishes that mitigating this source of mortality, assuming no change in the current immigration rate, would result in a rapid increase of the Valais population. The same conclusions would apply to other areas of Switzerland and Central Europe with similar, heavily anthropized landscapes. Based on this evidence we have approached the Swiss federal authorities so that they convince (if necessary through new laws) electrical companies to progressively mitigate all dangerous pylons present in the landscape. This has led to the publication of a well-documented brochure with a catalogue of recommendations and prescriptions ${ }^{13}$. But so far, despite several attempts, nobody could obtain from the head organizations of the numerous Swiss electrical companies that they actively commit themselves to mitigate dangerous pylons. It is as if these head organizations will not recognize the seriousness of the issue. In contrast to

\footnotetext{
12 Schaub, M., Aebischer, A., Gimenez, O., Berger, S., Arlettaz, R., 2010. Massive immigration balances high anthropogenic induced mortality in a stable Eagle Owl population: Lessons for conservation, Biological Conservation, 143, 1911-1918.

13 Anonymous, 2009. Vogelschutz an Starkstrom-Freileitungen mit Nennspannungen über $1 \mathrm{kV}$, Verband Schweizerischer Elektrizitätsunternehmen VSE, Bundesamt für Umwelt BAFU, Bundesamt für Verkehr BAV, Bundesamt für Energie BFE, Eidgenössisches Starkstrominspektorat ESTI, Geschäftsbereich Energie SBB, Netz-Anlagenmanagement.
}

this total failure of the top-down approach, our attempts to approach local electricity companies resulted in many dangerous pylons situated close to breeding sites to be mitigated at the company's own costs. These mitigations are even economically advantageous for a company because any case of electrocution on middle tension lines requires precisely localizing the short circuit (i.e. the dangerous pylon) to re-instate an operating electricity network. From a strategic viewpoint the question remains, however, why the bottom-up approach seems to work quite well, whereas the top-down approach has completely failed to deliver any positive outcome so far.

R.M.: This success might be linked to the social regulation at the local levels and the quality of the dialogue process. The conservation policy feasibility has to consider both local and global resistances to make the strategy effective. The values of biodiversity conservation to society are difficult to quantify. The importance of justifying and funding reintroduction programmes for instance is always challenged. You had to face this kind of difficulties in the situation of a major reintroduction programme, where the main difficulty appears to be, unexpectedly, to convince your peers (naturalists, ecologists and conservation biologists) to adopt a rational strategy rooted in sound scientific evidence.

Raphaël Arlettaz: Yes, I have been involved since the beginning in the project of the reintroduction of Bearded vulture into the European Alps. This magnificent raptor, which feeds on bone marrow, was extirpated from the Alps at the end of the 19th century. A reintroduction programme of birds raised in captivity was launched in 1986, which led to numerous successful reproductions since the nineties. The question which recently arose was when to stop releases knowing that reintroductions are very costly. Actually, at the time of its release to the wild a Bearded vulture cumulates costs up to $€ 70000$. To answer this question we built a markresighting model to estimate survival rates of Alpine Bearded vultures and evaluated risks of extinction of the population. The analysis showed that the extinction risk of the Alpine population under the currently prevailing circumstances is almost null ${ }^{14}$. The population could even stand a $50 \%$ increase in mortality while remaining stable, although we should remain vigilant regarding the emergence of new sources of mortality which may obliterate the demographic trajectory (e.g. the impact of poisoned baits applied against wolves recolonizing the Alps; the development of wind farms on Alpine ridges and passes). This means that the current rate of reproduction would be enough to more than compensate mortality,

\footnotetext{
14 Schaub, M., Zink, R., Beissmann, H., Sarrazin, F., Arlettaz, R., 2009. When to end releases in reintroduction programmes: demographic rates and population viability analysis of bearded vultures in the Alps, Journal of Applied Ecology, 46, 92-100.
} 
i.e. to sustain a positive development of the population. In other terms, releases could be stopped at once. This message was conveyed to the promoters of the international reintroduction programme, who, based on this sound piece of scientific evidence, decided to stop releases at several sites. Other actors, however, have decided to continue with releases, and even to create a new release site. This is against any logic, at least under the currently prevailing circumstances, because further releases can contribute only marginally to increasing population growth rate: adding 6 captive-raised birds a year to the Alpine population, which corresponds to the average figure over the last 20 years, would lead to a doubling of the population within 10 years, instead of 15 years if no additional releases were performed. Clearly, this is worth neither the effort nor the money. Of course the defenders of additional releases at a new release site in the Alps justify their strategy with other arguments than boosting population growth: optimizing sex ratio (although there is lack of evidence for an unbalanced sex ratio across the Alps) and injecting rare genes from the captive stock into the free-ranging population to increase genetic diversity (although reconnecting Alpine and Pyrenean Bearded vultures would be a much more promising way to achieve this). Without entering into too many details, and notwithstanding parallel political issues, what astonishes in this case is the difficulty to convince some of one's own peers (ecologists and conservation biologists) to make an appropriate and rational strategic decision, especially when the scientific evidence is so strong. At this point one can ask which solutions the sociological sciences would suggest for solving this kind of dilemma: how to improve the acceptance of the evidence by peers? What is particularly intriguing if not disappointing is that the issue has no inter-disciplinary dimension, contrary to the first two cases discussed earlier on, because here strategic decisions clearly lie within a guild of peers with similar educational background and even very convergent long-term conservation and restoration objectives. We had thus expected a much easier incorporation of scientific knowledge into strategic decisions. Is this situation not especially puzzling?

R.M.: This illustrate quite well that the problems are not always where we expect them intuitively. It happens also that the utilitarian justification of a conservation programme, as advocated to the stakeholders by the initiators of a project, are eventually not the reason why stakeholders played the game and contributed to its success.

Raphaël Arlettaz: I experienced such an itinerary in a project related to the Hoopoe, a bird of conservation concern in Central Europe. In Switzerland, in the early 90s, a single relict population remained in the Upper Rhone valley (Valais). Research carried out then showed that the population was probably suffering from a lack of suitable breeding cavities on the intensively cultivated plain, whilst prey abundance (Mole crickets) seemed to be sufficient ${ }^{15}$. As a remedy, we proposed to install numerous nest boxes in agricultural buildings and shacks so as to provide an unlimited offer of breeding sites. We approached the local authorities (services of agriculture and nature protection) for helping launch and finance a massive nest box campaign. In order to convince the local farmers to accept the installation of the nest boxes, Hoopoes were advocated for their pest control function: as Mole crickets may impact on the growth of vegetables, increasing the number of their principal predator could only exert positive effects on agricultural production. The installation of hundreds of nest boxes resulted in a rapid growth of the local Hoopoe population, from about 20 to 120 broods a year within only five years ${ }^{7}$. The once rare bird became popular again in the public, who had now many more opportunities to observe this magnificent species in the countryside, as well as among farmers who had become very enthusiastic about this rehabilitation project. Some farmers even approached us, asking for the installation of additional nest boxes in nonequipped buildings despite hundreds of boxes already available. Yet, we were very surprised to notice, when inquiring about their deep motivation for further favouring Hoopoes, that the main reason they usually invoked was the opportunity to come across these superb birds during their daily activities in the field. Astonishingly, the pest control role of Hoopoes was not mentioned at all by the farmers! This went far beyond our expectations: we had campaigned for Hoopoes basing our strategy on the utilitarian function they can represent in terms of pest control, but the deep motivation of several farmers eventually appeared to be of a more aesthetic or emotional nature. This case shows that conservation action can lead to unexpected changes in paradigms among stakeholders once tangible, concrete effects are visible in the real world. Specialists from the social sciences would possibly have envisioned this possibility beforehand, but this was a true revelation for us. Motto: don't discount the cascade effects which may result from a successful conservation action.

R.M.: Finally, your own experience showed that conservation biology is a field that should optimally integrate more and more the social and cultural dimensions. The conservation policy must be based on solid scientific evidence but also socially nested. At a period where science is challenged by participatory

\footnotetext{
15 Fournier, J., Arlettaz, R., 2001. Food provision to nestlings in the Hoopoe Upupa epops: Implications for the conservation of a small endangered population in the Swiss Alps, Ibis, 143, $2-10$.
} 
processes, with numerous invitations to act despite uncertainties, your concrete testimony on the failures and successes you encountered in the design and implementation of both your research and conservation actions showed that there is an obvious need to question prevalent norms and procedures, and understand social representations and power relationships. Your interpellation of social sciences on how they may contribute to such kind of conservation projects may feed their reflection on the place of the scientific expertise, the scientific models, the management tools and the environmental object that support the awareness raising and collective thinking in this kind of approach. To conclude,your personal engagement showed the growing interest of conservation projects for social and economic dimensions even if the project leaders do not always mobilize social sciences to develop social engineering but tend to develop collaborative approaches directly with local actors and stakeholders. Designing an effective biodiversity policy or enacting conservation action requires clarifying conservation goals, evaluating scientific evidences and being sensitive to the social context. In other words, mixing contextualized science and normal science. 